www.jmscr.igmpublication.org

Index Copernicus Value: 79.54

ISSN (e)-2347-176x ISSN (p) 2455-0450

crossref DOI: https://dx.doi.org/10.18535/jmscr/v7i5.158

\title{
A Study to assess the Effectiveness of Structured Teaching Programme on Knowledge Regarding Pre-Menstrual Syndrome among the Adolescent Girls at Selected School in Rural Area
}

\author{
Author \\ Mrs. Niza. Subramanian \\ Associate Professor, Samarth Nursing College, Dervan, \\ Ratnagiri District, Maharashtra
}

\begin{abstract}
Pre-menstrual syndrome is a combination of physical and mood disturbance that occur in the last half of a woman's menstrual after ovulation which normally end with the onset of the menstrual. Menstruation is still regarded as something unclean or dirty in India and the reaction to menstruation depends upon awareness and knowledge about the subject. Most girls are ignorant about the physiology of menstruation and therefore the first experience of menstruation is of fear, shame and disgust. The present study assessed the effectiveness of structured teaching program on knowledge regarding pre-menstrual syndrome among the adolescent girls at selected school in rural area. The design was adopted by the investigator in this study was pretest and post test quasi experimental design. A total of 30 adolescent girls were selected from the school by using convenient sampling technique. The purpose of the study was explained to the students and consent was taken from all the participants. A structured pretest questionnaire related to pre-menstrual syndrome were asked to them for scoring knowledge. The study found that adolescent girls had inadequate knowledge regarding pre-menstrual syndrome in pretest. After the STP on pre-menstrual syndrome there was a significant improvement in knowledge of the adolescent girls regarding pre-menstrual syndrome. The study concluded that the STP was effective in improving the knowledge of the adolescent girls regarding pre-menstrual syndrome. The formulated hypothesis was supported.

Keywords: Premenstrual syndrome, PMS, menstruation, menstrual cycle, menstrual hygiene.
\end{abstract}

\section{Introduction}

Adolescence in girls has been recognized as a special period in their life cycle that requires specific attention. This period is marked with onset of menarche Adolescent girls constitute a vulnerable group, particularly in India where female child is discriminated in the society. Menstruation is still regarded as something unclean or dirty in India and the reaction to menstruation depends upon awareness and knowledge about the subject. Most girls are ignorant about the physiology of menstruation and therefore the first experience of menstruation is of fear, shame and disgust. A fear inculcates in the adolescent girls that they will sin if they breaks these taboos. For these reasons, girls' attitudes and expectations about menstruation became very negative. Premenstrual syndrome is an array of symptoms that occurs during the second half of the menstrual cycle. The symptoms typically 
include one or more of the following. Depression, tiredness, irritability, anxiety, headache, breast swelling, tenderness, craving for sweet or salty foods, constipation and skin acne. Good menstrual health encompasses personal hygiene, mental health, adequate nutrition and correct use of absorbents such as cloth or sanitary napkins. As health team members, nurses can make the adolescent girls aware about this. So that they will be in a better position to practice the hygienic ways

\section{Statement of the problem}

"A study to assess the effectiveness of structured teaching program on knowledge regarding premenstrual syndrome among the adolescent girls at selected school in rural area.

\section{Objectives}

1. To assess the knowledge regarding premenstrual syndrome among the adolescent girls.

2. To assess the effect of structured teaching Program on knowledge regarding premenstrual syndrome among the adolescent girls.

3. To find the association between post test knowledge regarding pre-menstrual syndrome among the adolescent girls with their selected demographic variables.

\section{Hypotheses}

$\mathrm{H}_{0}$ : There will not be any significant difference between pre test knowledge post test knowledge.

$\mathrm{H}_{1}$ : There will be significant difference between pre test knowledge score and post test knowledge score.

\section{Materials and Methods \\ Research Approach}

In the present study investigator aims to determine the effectiveness of structured teaching program on knowledge pre-menstrual syndrome among the adolescent girls using a quantitative research approach.

\section{Research Design}

Quasi experimental research design that is One group pre test and post test design.

\section{Setting of the study}

The study were carried out in primary school in sawarda (kasarwadi) and rural area.

\section{Population}

The population for the study consisted of the adolescent girls presented in the selected school during the data collection time.

\section{Sample Size}

30 adolescent girls

\section{Sampling Technique}

The sampling technique used in this study was non-probability convenient sampling.

\section{Tool and Techniques}

Based on the objectives of the study, the investigator selected the structured questionnaire as a tool for assessing knowledge.

\section{Data Collection Technique}

The data gathering process was done from after securing the permission from concerned authority, the investigator contacted to the study samples. Purpose of the study, right to confidentiality and right to withdrawal was explained to each sample and additional doubts asked by them were cleared with appropriate explanation. After confirming their participation, each sample was given an identification number to maintain confidentiality.

Pretest Structured questionnaire related to premenstrual syndrome were given to them for scoring knowledge. After pretest STP was given to them and post test conducted after a week. The entire sample co-operated well with the investigator during the data collection period

\section{Results}

Distribution of data related to pre test and post test knowledge score of adolescent girls regarding premenstrual syndrome. 
Table No.1 Pre and post test knowledge score of adolescent girls regarding premenstrual syndrome $\mathrm{n}=30$

\begin{tabular}{|l|c|c|c|c|c|}
\hline \multirow{2}{*}{} & \multirow{2}{*}{ Level of Scores } & \multicolumn{2}{|c|}{ Pre-test } & \multicolumn{2}{c|}{ Post test } \\
\cline { 3 - 6 } & & $\mathrm{N}$ & $\%$ & $\mathrm{~N}$ & $\%$ \\
\hline 1 & Poor(1_8) & 15 & 50 & 5 & 16.67 \\
\hline 2 & Average(9_17) & 10 & 33.33 & 5 & 16.67 \\
\hline 3 & Good(17_25) & 5 & 16.67 & 20.00 & 66.67 \\
\hline Total & & 30 & 100 & 30 & 100 \\
\hline
\end{tabular}

Table no. 1 sows that, before structured teaching program, 50\% of them poor knowledge score, $33.33 \%$ of them are having average knowledge, $16.67 \%$ of them are having good knowledge score
After structured teaching program, $16.67 \%$ of them poor knowledge score, $16.67 \%$ of them are having average knowledge, $66.67 \%$ of them are having good knowledge

Graph No.1 Pre and Post Knowledge Score Adolecent Girls in the study group

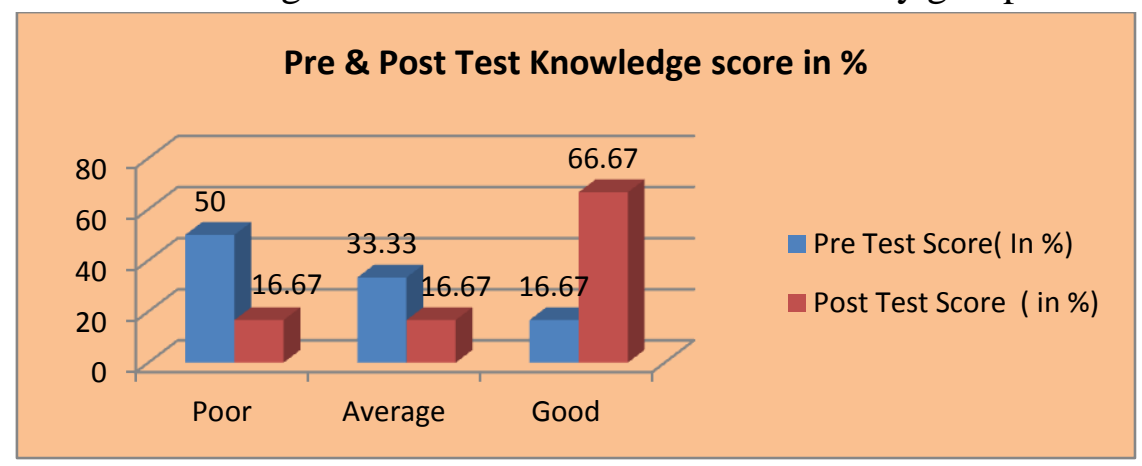

Graph no 1: before structural teaching program, $50 \%$ of them poor knowledge score, $33.33 \%$ of them are having average knowledge, $16.67 \%$ of them are having good knowledge score

After structural teaching program, $16.67 \%$ of them poor knowledge score, $16.67 \%$ of them are having average knowledge, $66.67 \%$ of them are having good knowledge
Analysis of data to assess the effectiveness of structured teaching program on knowledge and practice by comparison of pre and post test knowledge and practice score among adolescent girls regarding premenstrual syndrome.

Table no.2 Comparison of pre and post test knowledge score

\begin{tabular}{|c|l|c|c|c|c|c|}
\hline \multicolumn{2}{|c|}{} & Mean & $\mathrm{N}$ & Std. Deviation & t value & P value \\
\hline Pair 1 & Pre_test_score & 14.77 & 30 & 4.651 & \multirow{2}{*}{6.714} & \multirow{2}{*}{0.000} \\
\cline { 1 - 5 } & Post_test_score & 19.40 & 30 & 2.660 & & \\
\hline
\end{tabular}

Table 2. shows that, the calculated value of $t$ statistics is 6.741 and p-value (sig. 2- tailed) is 0.000

Conclusion: As the $\mathrm{p}$-value $(0.000)<0.05$ we accept $\mathrm{H}_{1}$ and concluded that there is statistical significant difference between pre and post test mean knowledge scores in adolescents at 5\% level of Significance. Hence the research hypothesis was accepted that means there is a significant difference between pretest and post test knowledge. Thus the structured teaching program is significantly effective in increasing the knowledge of adolescent girls regarding premenstrual syndrome. 
Graph No 2. Comparison of pre and post test knowledge score

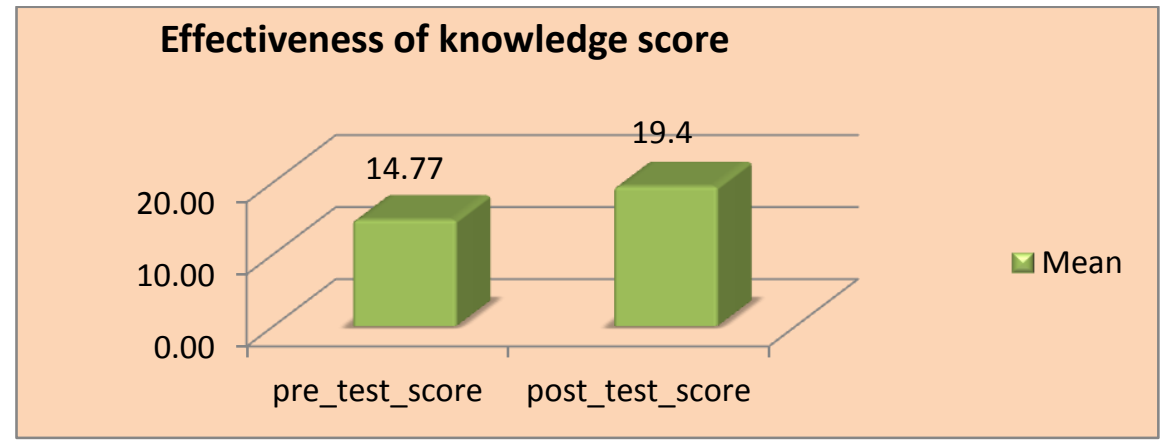

Graph no.2. shows that Pretest knowledge score regarding premenstrual syndrome mean 14.77 and posttest knowledge score regarding premenstrual syndrome mean 19.40

\section{Major Findings of the study}

Findings related to pre test and post test knowledge score of adolescent girls regarding premenstrual syndrome

Before structured teaching program, 50\% of them poor knowledge score, $33.33 \%$ of them are having average knowledge, $16.67 \%$ of them are having good knowledge score

After structured teaching program, $16.67 \%$ of them poor knowledge score, $16.67 \%$ of them are having average knowledge, $66.67 \%$ of them are having good knowledge

\section{Findings related to effectiveness of structured teaching program on knowledge regarding premenstrual syndrome.}

The pre test knowledge score is 14.77. After the administration of structured teaching program the mean post test knowledge score is 19.40. The calculated value of $t$ statistics is 6.741 and $p$-value (sig. 2- tailed) is 0.000

As the $\mathrm{p}$-value $(0.000)<0.05$ we accept $\mathrm{H}_{1}$ and concluded that there is statistical significant difference between pre and post test mean knowledge scores in adolescents at 5\% level of Significance. So there was a significant difference between pre and post knowledge adolescent girls regarding premenstrual syndrome. Thus the structured teaching program is significantly effective in increasing the knowledge of adolescent girls regarding premenstrual syndrome. Hence the Hypothesis is supported. That is post test knowledge score is more than the pre test knowledge score.

\section{Conclusion}

The findings of the study show that there is highly significant difference between the pre test and post test knowledge score of the study group. Hence the Structured teaching program significantly brought out an improvement in knowledge among the adolescent girls regarding premenstrual syndrome.

\section{Implications and Recommendations}

- Today nurses are actively generating, publishing and applying research in practice to improve client care and enhance scientific knowledge base of Nursing.

- The study helps the nurse researcher to develop insight into the development of teaching module and materials for premenstrual syndrome towards promoting awareness among adolescent girls. There is a lot of scope for exploring this area research can be done on the various beneficial effects of premenstrual syndrome and acknowledge of adolescent girls regarding premenstrual syndrome.

\section{Bibliography}

1. World Health Organization. Programming for adolescent health and development. WHO Technical Report Series. 1996 ;886(2) 
2. Adolescent Reproductive and Sexual Health. United Nations Population Fund India. 2010 [cited2012Nov15].

3. Drakshayani DK Ventaka RP, A study on menstrual hygiene among rural adolescent girls. Ind J Med Sci 1994; 48(6):139 - 43.

4. Oyebola DO, Female Reproduction. Essential Physiology for Students of Medicine, Pharmacy and Related Disciplines. Ibadan: Nihort Press; 2002. pp.232-234

5. Dasgupta A, Sarkar M. Menstrual Hygiene: How Hygienic is the Adolescent Girl? Indian journal of community medicine [serial on the Internet]. 2008 [cited 2012 Aug 6].;33(2)

6. Bheenaveni R. Beliefs and practices in women health. Promote healthy life. 2010

7. Stubbs ML. Cultural perceptions and practices around menarche and adolescent menstruation in the United States. Annals of the New York Academy of Sciences. 2008;11(35)

8. Water Aid's Mission . Is menstrual hygiene and management an issue for adolescent school girls?.2009[cited2012Jun6].

9. Ranjan R, Sharama RK. Gender differentials in the knowledge of RTI and STI in India: Evidence from RCH-RHS II-survey. Inter-regional seminar on reproductive health, unmet needs and poverty: Issues of access and quality of service, Bangkok. Committee for International Cooperation in National Research in Demography [homepage on the Internet]. 2002 [cited 2012 Jun6].

10. Gender and Sanitation R. Breaking taboos, improving lives. Tearfund. [homepage on the Internet].Nodate[cited2012Jun8].

11. Indian Council of Medical Research (I.C.M.R). Knowledge and practices of adolescent girls. In Reproductive health.
ICMR annual report, New Delhi [serial on the Internet]. 2005 - 2006 [cited 2012 Aug 12]; 74 INCLEN international clinical epidemiology network. 1998 - 2001 Available from: www.inclen.org.

12. ,Sharma P,Saha R.Problems related to menstruation and their effect on daily routine of students;Maulana Azad Medical College Delhi, India. Asia Pac, Public Health.

13. Daley A, Exercise and premenstrual symptomatology; a comprehensive review; university of Birmingham, United Kingdom. J womens Health (Larchmt). Jun; 18(6): 855-9

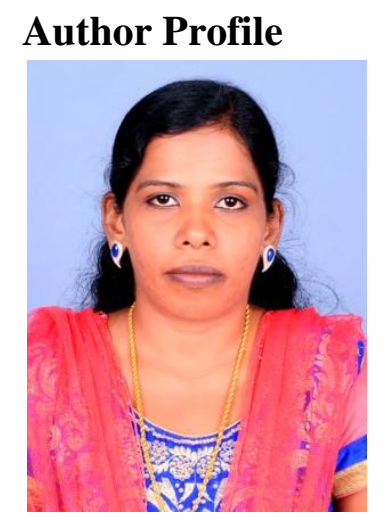

Mrs. Niza.S, M.Sc Nursing speciality in obstetrics and gynaecology Nursing working as vice Principal at Samarth Nursing College, Dervan, Ratnagiri District, Maharashtra. She received B.Sc Nursing degree in the year of 2001 to 2006 at Madras Medical College, Dr. M.G.R University, Tamil Nadu. Received M.Sc Nursing in 2008 to 2010 at Rani Meyyamai College Of Nursing Annmalai University, Tamil Nadu. Worked in Godavari College Of Nursing Jalgaon in the year of 2011 to 2013 as a lecturer and she was the research guide for M.Sc Nursing students under M.U.H.S. In Samarth Nursing College she is working since 2014 as associate professor cum vice principal and guided M.Sc Nursing students in research work. 